\title{
Seasonal stability in parasite assemblages of the Brazilian flathead, Percophis brasiliensis (Perciformes: Percophidae): predictable tools for stock identification
}

\author{
Paola E. Braicovich ${ }^{1,2}$ and Juan T. Timi ${ }^{1,2}$
}

\author{
${ }^{1}$ Laboratorio de Parasitología, Departamento de Biología, Facultad de Ciencias Exactas y Naturales, Universidad Nacional de Mar \\ del Plata, Funes 3350, (7600) Mar del Plata, Argentina; \\ ${ }^{2}$ Consejo Nacional de Investigaciones Científicas y Técnicas (CONICET)
}

\begin{abstract}
A comparison of the composition and structure of parasite communities of the Brazilian flathead, Percophis brasiliensis Quoy et Gaimard (Perciformes: Percophidae) among seasons during one year was carried out in the Argentine Sea. A total of 195 fish specimens were examined and 25 parasite species were found. Parasite communities in seasonal samples showed a high degree of homogeneity in taxonomic composition and infection levels. Similarity analysis showed that the seasonal stability within and between samples was constant in both the composition and community structure throughout the year. Parasites can, therefore, be considered predictable markers for fish stock identification, independently of the season of capture, at least on an annual scale.
\end{abstract}

Keywords: parasite communities, temporal stability, biological tags, fish populations, south-west Atlantic

In recent decades parasite ecologists have searched for recurrent and predictable patterns in order to determine whether there are general rules that govern the structure of parasite assemblages (Poulin 2007). As a result, an increasing number of macroecological studies have sought to identify the key determinants of parasite community structure (Gotelli and Rohde 2002, Luque et al. 2004, Poulin 2004, Mouillot et al. 2005, Luque and Poulin 2008) and a variety of ecological and evolutionary processes, historical events and geographical contingencies have been proposed as causal factors of the observed patterns in parasite species diversity (Poulin 2004). However, much available evidence derives from studies without replication in both space and time (Poulin 2001), and the spatial and temporal variations in community structure, and thus the detection of relevant local or short-term processes, have generally been ignored in efforts to identify patterns in fish parasite assemblages (Díaz and GeorgeNascimento 2002, Poulin and Valtonen 2002, Vidal-Martínez and Poulin 2003, González and Poulin 2005).

In contrast, the spatial variability in the composition and abundance of parasite assemblages makes possible the use of parasites as biological tags for identifying fish stocks. The use of parasites to provide information on the fish stock discreteness is a well-established and broadly accepted tool in fisheries management (MacKenzie and Abaunza 1998, Begg and Waldman 1999, MacKenzie
2002, Power et al. 2005): however, its implementation requires a high degree of temporal repeatability in the composition and structure of parasite communities to allow comparative studies. Nevertheless, most studies using parasites as indicators have analyzed just a single sample at each locality and thus the potential temporal variability of parasite communities, and how this may affect their use in identifying fish stocks, have been largely ignored (Chavez et al. 2007).

In the south-west Atlantic, few studies have attempted to use parasites to delineate marine fish populations (Timi 2007). However, this approach has proved to be successful in discriminating stocks of all fish species to which it has been applied (Cremonte and Sardella 1997, Timi 2003, Sardella and Timi 2004, Timi et al. 2005, 2008, 2009), including the host of interest in the present study, the Brazilian flathead, Percophis brasiliensis Quoy et Gaimard (Perciformes: Percophidae) (Braicovich and Timi 2008).

Parasites have been used to identify three stocks of P. brasiliensis off the coast of Argentina and Uruguay (Braicovich and Timi 2008). In these flathead populations, the authors also confirmed the existence of a subset of parasite species that could be used as regional biological tags, which allowed not only fish populations but also fish assemblages to be identified. The use of subsets of parasites as biological tags had been predicted by Timi (2007), and was later corroborated by Timi et al. (2008),

Address for correspondence: P.E. Braicovich, Laboratorio de Parasitología, Departamento de Biología, Facultad de Ciencias Exactas y Naturales, Universidad Nacional de Mar del Plata, Funes 3350, (7600) Mar del Plata, Argentina. Phone: +54 2234752426 ; Fax: +54 223 4753150; E-mail: braicovi@mdp.edu.ar 
but this prediction also relies on the assumption of temporally repeatable parasite burdens. There are few studies on seasonal repeatability of population and community attributes of fish parasites in the south-west Atlantic. Despite this, some evidence does support their occurrence: recently, Timi et al. (2009) showed that parasites of the Brasilian sandperch Pinguipes brasilianus Cuvier were seasonally stable and that locality effects exceeded temporal variation in determining the composition and structure in parasite assemblages. However, these authors did not present data for a complete annual cycle within each locality.

Seasonal variations in abiotic conditions can exert strong pressures on parasite populations, playing an important role in shaping population fluctuations (Altizer et al. 2006). For example, the transmission and survival of free-living stages are influenced by environmental conditions, either directly or through the effects on other hosts involved in their life cycles (Pietrock and Marcogliese 2003). Seasonally induced annual changes in host and parasite biology are known to fluctuate cyclically, but there is a growing awareness of the importance of multiyear oscillations and even chaotic dynamics (Altizer et al. 2006). In short, because of temporal variability, a parasite species identified as a suitable biological tag in a given place and time could prove to be an unreliable marker in other seasons or in future studies. It is therefore desirable to assess the seasonal repeatability of fish-parasite systems in order to establish their usefulness as predictable tools not only for delineation of host populations, but also the identification of harvest locations.

The aim of this study was to determine whether parasite populations and communities of $P$. brasiliensis caught at a single locality display seasonal variations along a complete annual cycle.

\section{MATERIALS AND METHODS}

To assess the effect of seasonality on parasite burdens, a total of 195 specimens of $P$. brasiliensis were collected in four different seasons during a one-year period: Winter 2005, $\mathrm{n}=49$, mean total length (TL) (range): $55.2(42-73) \mathrm{cm}$; Spring 2005, $\mathrm{n}=51$, mean TL(range): $56.6(44-71) \mathrm{cm}$; Summer 2006, $\mathrm{n}=50$, mean TL(range): 55.3 (46-67) cm; Autumn 2006, $\mathrm{n}=45$, mean TL(range): 56.8 (49-64) cm. Data of Spring samples were taken from a previous study by Braicovich and Timi (2008). Fish were caught by trawling 30 miles off the coast of the city of Mar del Plata, Argentina $\left(38^{\circ} \mathrm{S} ; 57^{\circ} \mathrm{W}\right)$ and either kept fresh or frozen in plastic bags at $-18^{\circ} \mathrm{C}$ until examination. After defrosting, the TL of each flathead was measured to the nearest $\mathrm{cm}$ and a necropsy was conducted under a stereoscopic microscope. Fish length was compared among samples by means of a oneway Anova test. Prevalence and mean abundance (sensu Bush et al. 1997) were calculated for each parasite species in each sample. Chi square analyses and a posteriori multiple comparisons for proportions were used to test for significant differences in prevalence between seasons. Kruskal-Wallis and a posteriori Dunn's tests for unequal samples were used to analyse the effects of seasons on abundance of each parasite species. Both analyses were performed for species with prevalence $>10 \%$ in at least one of the seasons (component species; Bush et al. 1990). Larval cestodes designated in the present study as Scolex polymorphus represent a complex of species (Chambers et al. 2000), each of which may display different temporal dynamics and/or geographical distribution. They are therefore not a reliable indicator of similarity among host populations (Braicovich and Timi 2008) and were excluded from all comparisons and multivariate analyses.

Similarity percentage (SIMPER, Clarke 1993) analyses based on Bray-Curtis similarity were conducted to determine which parasite species were consistently important to similarities within and between parasite assemblages. Typical species were identified as those that made substantial contributions to average within-assemblage similarity and doing it consistently by displaying a high ratio between that contribution and its standard deviation. Discriminator species were defined as those making high contributions to the average dissimilarity of parasite assemblages in different seasons. Consistently discriminating species displayed a high ratio between their contribution to average dissimilarity and its standard deviation (Clarke and Gorley 2006).

Parasite community composition was compared among sampling periods in a permutation-based one-way analysis of similarity based on Bray-Curtis similarities (ANOSIM, Clarke 1993). The statistical significance of the differences among seasons was assessed after 10,000 permutations on abundance data.

A discriminant analysis (DA), based on Mahalanobis distances, was used to reveal differences between seasons and to identify which parasite species were responsible for these differences. Analyses were computed on square root-transformed abundance data using the Brodgar 1.8 package (Brodgar 2000). All multivariate analyses included only parasites reaching the status of component species in at least one of the samples.

\section{RESULTS}

Mean host TL did not vary significantly across the four seasons $\left(\mathrm{F}_{50,3}=0.76, P>0.05\right)$. All Brazilian flatheads were parasitized by at least one of the 25 species of parasites listed in Table 1. A total of 227,575 metazoan parasites were found in the total sample (total mean abundance \pm standard deviation: 1,167 \pm 946 ). Larval endoparasites accounted for the $99.7 \%$ of all individuals found and dominated all infracommunities. The larval cestode Grillotia carvajalregorum (=Progrillotia dollfusi Carvajal et Rego, 1983) was particularly common, accounting for $60 \%$ of all parasites and dominating in $98.5 \%$ of infracommunities. Adult endoparasites accounted for $40 \%$ of species richness, and were represented mainly by hemiuroid digeneans, but their relative abundance was exceedingly low ( $0.3 \%$ of all individuals). Ectoparasites were represented only by gnathiid larvae (praniza and zuphea).

Parasite communities in seasonal samples of $P$. brasiliensis showed a high degree of homogeneity in taxonomic composition and infection levels. Only those parasites not reaching the status of component species (mainly those at adult stages) showed seasonal variability in their occurrence. Indeed, no significant differences were observed 
Table 1. Taxonomic composition, prevalence (P) and mean abundance \pm standard deviation (MA \pm S.D.) of parasites of Percophis brasiliensis from the coast of Mar del Plata, Argentina.

\begin{tabular}{|c|c|c|c|c|c|c|c|c|c|}
\hline & \multirow[b]{2}{*}{ Stage } & \multicolumn{2}{|c|}{ Winter 2005} & \multicolumn{2}{|c|}{ Spring 2005} & \multicolumn{2}{|c|}{ Summer 2005/06 } & \multicolumn{2}{|c|}{ Autumn 2006} \\
\hline & & $\mathrm{P}$ & $\mathrm{MA} \pm \mathrm{S} . \mathrm{D}$ & $\mathrm{P}$ & $\mathrm{MA} \pm$ S.D. & $\mathrm{P}$ & $\mathrm{MA} \pm \mathrm{S} . \mathrm{D}$ & $\mathrm{P}$ & $\mathrm{MA} \pm \mathrm{S} . \mathrm{D}$ \\
\hline \multicolumn{10}{|l|}{ DIGENEA } \\
\hline Prosorhynchus sp. & Metacercaria & 14.3 & $0.2 \pm 0.5$ & 9.8 & $0.2 \pm 0.5$ & 10.0 & $0.1 \pm 0.4$ & 6.7 & $0.1 \pm 0.9$ \\
\hline $\begin{array}{l}\text { Cardicola ambrosioi Braicovich, Etchegoin, } \\
\text { Timi et Sardella, } 2006\end{array}$ & Adult & 4.1 & $0.2 \pm 1.1$ & 2.0 & $0.02 \pm 0.1$ & 2.0 & $0.06 \pm 0.4$ & 2.2 & $0.02 \pm 0.2$ \\
\hline Aponurus laguncula Looss, 1905 & Adult & 0.0 & 00 & 0.0 & 0.0 & 6.0 & $0.2 \pm 1.0$ & 2.2 & $0.02 \pm 0.2$ \\
\hline Derogenes varicus (Müller, 1784) & Adult & 4.1 & $0.06 \pm 0.3$ & 0.0 & 0.0 & 0.0 & 0.0 & 2.2 & $0.09 \pm 0.8$ \\
\hline Ectenurus virgulus Linton, 1910 & Adult & 0.0 & 0.0 & 3.9 & $0.1 \pm 0.3$ & 4.0 & $0.08 \pm 0.4$ & 0.0 & 0.0 \\
\hline $\begin{array}{l}\text { Elytrophalloides oatesi (Leiper et Atkinson, } \\
\text { 1914) }\end{array}$ & Adult & 6.1 & $0.7 \pm 3.1$ & 0.0 & 0.0 & 0.0 & 0.0 & 2.2 & $0.02 \pm 0.2$ \\
\hline Lecithochirium microstomum Chandler, 1935 & Adult & 18.4 & $1.0 \pm 3.3$ & 13.7 & $0.4 \pm 1.5$ & 36.0 & $2.2 \pm 4.0$ & 35.6 & $3.1 \pm 21.4$ \\
\hline Lecithocladium cristatum (Rudolphi, 1819) & Adult & 8.2 & $1.1 \pm 5.2$ & 3.9 & $0.6 \pm 3.4$ & 0.0 & 0.0 & 0.0 & 0.0 \\
\hline Parahemiurus merus (Linton, 1910) & Adult & 2.0 & $0.02 \pm 0.1$ & 0.0 & 0.0 & 0.0 & 0.0 & 2.2 & $0.02 \pm 0.2$ \\
\hline Hemiuridae & Metacercaria & 0.0 & 0.0 & 0.0 & 0.0 & 0.0 & 0.0 & 2.2 & $0.02 \pm 0.2$ \\
\hline
\end{tabular}

\section{CESTODA}

Scolex polymorphus Müller, 1784

Grillotia carvajalregorum Menoret et Ivanov, 2009

Callitetrarhynchus gracilis (Rudolphi, 1819) Nybelinia sp.

Bothriocephalidea

NEMATODA

Anisakis simplex s.1. (Rudolphi, 1809)

Contracaecum sp.

Cucullanus sp.

Hysterothylacium sp.

Terranova galeocerdonis (Thwaite, 1927)

Moravecia argentinensis Braicovich,

Moravec et Timi, 2007

ACANTHOCEPHALA

Corynosoma australe Johnston, $1937 \quad$ Cystacanth

Corynosoma cetaceum Johnston et Best, 1942 Cystacanth

Bolbosoma sp.

ISOPODA

Gnathiidae gen. sp.

Praniza

Plerocercoid

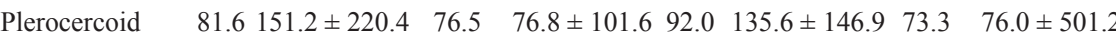
$\begin{array}{lllllllll}\text { Plerocercus } & 100 & 668.2 \pm 492.1 & 100 & 957.9 \pm 949.0 & 100 & 844.2 \pm 775.8 & 100 & 739.7 \pm 537.5\end{array}$

$\begin{array}{lll}12.2 & 0.2 \pm 0.5 \quad 33.3\end{array}$

$24.5 \quad 0.3 \pm 0.6 \quad 39.2$

$2.0 \quad 0.02 \pm 0.1 \quad 7.8$

$0.5 \pm 1.432 .0$

$0.5 \pm 0.815 .6$

$0.16 \pm 1.4$

$2.03 \pm 8.740 .0$

$0.6 \pm 1.0 \quad 46.7$

$1.0 \pm 7.0$

$0.08 \pm 0.3 \quad 4.0$

$0.04 \pm 0.2 \quad 0.0$

0.0

3rd-stage larva $\quad 44.9 \quad 1.1 \pm 1.9 \quad 43.1$

3rd-stage larva $\quad 2.0 \quad 0.02 \pm 0.1 \quad 3.9$

$1.3 \pm 2.5 \quad 40.0$

$0.9 \pm 1.7 \quad 57.8$

$\begin{array}{ll}0.0 & 2.2\end{array}$

$2.8 \pm 18.8$

$0.06 \pm 0.3 \quad 0.0$

$\begin{array}{ll}0.0 & 0.0\end{array}$

$0.04 \pm 0.4$

$0.0 \quad 0.0$

$\begin{array}{rr}0.04 \pm 0.3 & 0.0 \\ 38.7 \pm 54.6 & 100\end{array}$

$75.6 \pm 104.7 \quad 100$

$0.1 \pm 0.6 \quad 0.0$

$1.2 \pm 1.552 .0$

$\begin{array}{ll}0.0 & 2.2\end{array}$

$67.4 \pm 437.1$

$0.02 \pm 0.3$

$0.9 \pm 1.8 \quad 52.9$

$1.1 \pm 1.5 \quad 40.0$

$0.7 \pm 5.0$

Table 2. Breakdown of average similarity of parasite infracommunities of Percophis brasiliensis within sampling seasons into contributions from each parasite species. Only those with a cumulative contribution $>90 \%$ are included.

\begin{tabular}{|c|c|c|c|c|c|c|c|c|}
\hline \multirow{3}{*}{ Average similarity } & \multicolumn{2}{|c|}{ Winter } & \multicolumn{2}{|c|}{ Spring } & \multicolumn{2}{|c|}{ Summer } & \multicolumn{2}{|c|}{ Autumn } \\
\hline & \multicolumn{2}{|c|}{56.27} & \multicolumn{2}{|c|}{56.68} & \multicolumn{2}{|c|}{59.29} & \multicolumn{2}{|c|}{57.75} \\
\hline & $\mathrm{AS} / \mathrm{SD}^{\mathrm{a}}$ & $\%^{\mathrm{b}}$ & $\mathrm{AS} / \mathrm{SD}$ & $\%$ & $\mathrm{AS} / \mathrm{SD}$ & $\%$ & $\mathrm{AS} / \mathrm{SD}$ & $\%$ \\
\hline Grillotia carvajalregorum & 2.23 & 85.38 & 2.37 & 83.22 & 2.61 & 75.17 & 2.76 & 78.49 \\
\hline Corynosoma australe & 1.53 & 11.00 & 1.32 & 11.36 & 1.70 & 14.83 & 1.50 & 14.35 \\
\hline
\end{tabular}

${ }^{a}$ Average contribution to the total average similarity/standard deviation; ${ }^{b}$ percentage of total similarity contributed by each species.

Table 3. Breakdown of average dissimilarity of parasite infracommunities of Percophis brasiliensis between sampling seasons into contributions from each parasite species. Species are ordered in decreasing contribution to winter-spring comparison. Only those with a cumulative contribution $>90 \%$ are included.

\begin{tabular}{|c|c|c|c|c|c|c|c|c|c|c|c|c|}
\hline \multirow{3}{*}{ Average dissimilarity } & \multirow{2}{*}{\multicolumn{2}{|c|}{$\frac{\text { Winter-Spring }}{43.68}$}} & \multirow{2}{*}{\multicolumn{2}{|c|}{$\frac{\text { Winter-Summer }}{43.64}$}} & \multirow{2}{*}{\multicolumn{2}{|c|}{$\frac{\text { Winter-Autumn }}{42.01}$}} & \multirow{2}{*}{\multicolumn{2}{|c|}{$\frac{\text { Spring-Summer }}{42.13}$}} & \multirow{2}{*}{\multicolumn{2}{|c|}{$\frac{\text { Spring-Autumn }}{41.20}$}} & \multirow{2}{*}{\multicolumn{2}{|c|}{$\frac{\text { Summer-Autumn }}{40.10}$}} \\
\hline & & & & & & & & & & & & \\
\hline & $\mathrm{AS} / \mathrm{SD}^{\mathrm{a}}$ & $\%$ b & $\mathrm{AS} / \mathrm{SD}$ & $\%$ & $\mathrm{AS} / \mathrm{SD}$ & $\%$ & $\mathrm{AS} / \mathrm{SD}$ & $\%$ & $\mathrm{AS} / \mathrm{SD}$ & $\%$ & $\mathrm{AS} / \mathrm{SD}$ & $\%$ \\
\hline Grillotia carvajalregorum & 1.58 & 72.97 & 1.52 & 67.72 & 1.54 & 70.36 & 1.52 & 67.86 & 1.54 & 69.56 & 1.47 & 66.48 \\
\hline Corynosoma australe & 1.27 & 17.56 & 1.39 & 16.40 & 1.28 & 19.06 & 1.31 & 17.72 & 1.19 & 20.18 & 1.36 & 18.36 \\
\hline Hysterothylacium sp. & - & - & 0.95 & 14.25 & 1.04 & 8.49 & 1.00 & 12.94 & 1.07 & 8.37 & 1.00 & 13.19 \\
\hline
\end{tabular}

${ }^{a}$ Average contribution to the total average dissimilarity/standard deviation; ${ }^{b}$ percentage of total dissimilarity contributed by each species. 
Table 4. Discriminant analysis classification showing the numbers and percentages of Percophis brasiliensis classified in each season (rows correspond to group memberships, number of correctly classified fish in each sample in bold).

\begin{tabular}{|c|c|c|c|c|c|}
\hline & Winter & Spring & Summer & Autumn & $\%{ }^{*}$ \\
\hline Winter & 26 & 12 & 4 & 7 & 53.06 \\
\hline Spring & 12 & 19 & 12 & 8 & 37.25 \\
\hline Summer & 12 & 6 & 24 & 8 & 48.00 \\
\hline Autumn & 10 & 10 & 4 & 21 & 46.67 \\
\hline
\end{tabular}

*Percentage of correctly classified fish per season.

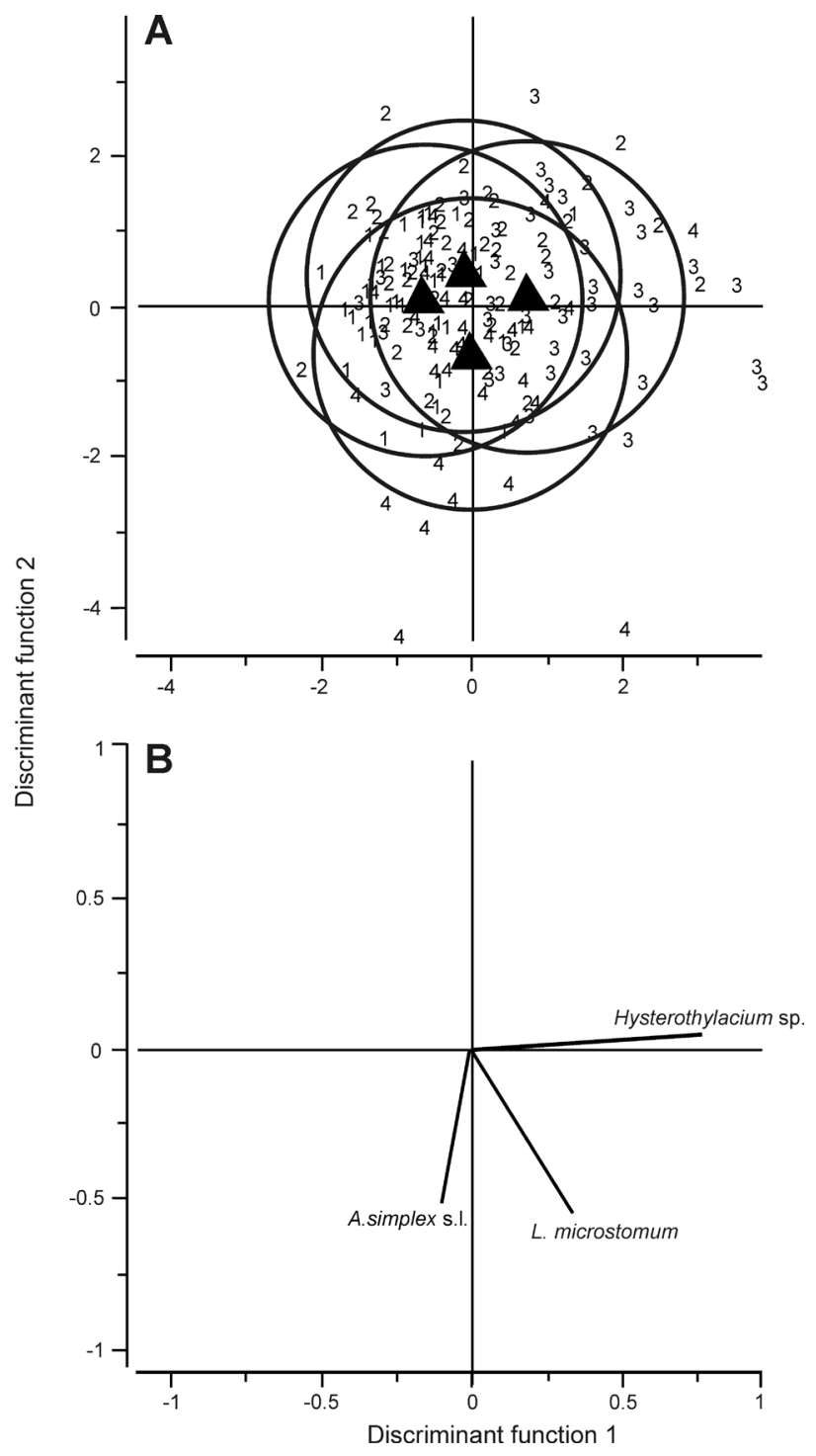

Fig. 1. A. Samples scores of the first two discriminant functions for specimens of Percophis brasiliensis from four seasons from Mar del Plata cost. Triangles are group means; the circle around group means are the $90 \%$ tolerance regions (i.e., $90 \%$ of the observations in a group are expected to lie in this region). 1, winter; 2, spring; 3, summer; 4, autumn. B. Canonical correlations between the first two discriminant functions and the parasites and species scores as variables of Percophis brasiliensis. for prevalence among seasons in any component parasite species (all $P>0.05$ ). Mean abundance was also similar among seasons for most of these species. The only component species showing significant seasonal variations was Hysterothylacium sp., which was less abundant in winter than in summer and autumn $\left(\mathrm{H}_{3}=27.13, P<0.01\right)$.

Average similarity within seasonal samples was nearly constant throughout the year (Table 2). Grillotia carvajalregorum and Corynosoma australe were typical species that contributed substantially $(>90 \%)$ to the average similarity in all seasons. Average dissimilarity values between pairs of seasons were low and also showed little seasonal variation (Table 3), therefore, pairwise average similarity between seasons (calculated as 100 minus average dissimilarity and ranging between 56.32 and 59.90) were similar to those within season. The most important and consistent discriminators among all samples were the typical G. carvajalregorum and C. australe. Hysterothylacium sp. also made important contributions to dissimilarity but did so less consistently.

Parasite communities varied less between seasons than within seasons. Similarity-based multivariate analysis showed that the four samples did not differ significantly in their parasite species composition (Global $R_{\text {ANOSIM }}: 0.001$, $P=0.40$ ), indicating that within-season similarity did not exceed among-seasons similarity in parasite assemblages. In effect, parasite communities in individual fish caught during any given season were as similar to one other as to those in fish caught in different seasons.

Similarly, DA showed that the samples collected in different seasons were highly homogeneous. The first two discriminant functions explained $87.2 \%$ of the variance, contributing $53.3 \%$ (eigenvalue $=0.252$ ) and $33.9 \%$ (eigenvalue $=0.160)$, respectively. Although a significant group effect was observed (Wilks' $\lambda=0.649, \mathrm{~F}_{(33,534.03)}=$ 2.56, $P<0.01)$, the dimensionality test showed significant group separation in only one dimension $\left(\chi_{(20)}^{2}=38.8\right.$, $P<0.01)$. Individual fish from all seasons clumped together in the bi-dimensional space (Fig. 1.A) and only $47 \%$ of hosts were correctly classified with respect to season (Table 4). The importance of each parasite species with respect to discrimination between seasons, evaluated as canonical correlations between discriminant functions and species scores as variables, showed that Hysterothylacium sp. was the most important species in determining the position of samples, its exclusion from the analysis producing a decrease of the total sum of Mahalanobis distances of $26.2 \%$. Hysterothylacium $\mathrm{sp}$. was clearly related to fish from summer, and was followed in importance by Lecithochirium microstomum (14.5\%) and Anisakis simplex s. 1. (14.4\%), both related to summer and autumn samples (Fig. 1.B). Contributions of the remaining parasite taxa were all lower than $10 \%$. 


\section{DISCUSSION}

At present, the parasite fauna of Percophis brasiliensis along its distributional range is known to contain 27 species of metazoans (Braicovich et al. 2009). However, artifacts such as sampling effort can affect richness estimates because both the number of hosts examined and the number of surveys conducted tend to co-vary with the number of species found in a community (Walther et al. 1995). Sampling over several seasons can increase the likelihood of detecting rare parasites (Zander 2005). Indeed, three previously unrecorded parasite species were found in 144 flatheads newly collected, namely Hemiuridae metacercariae, Cucullanus sp. and Bolbosoma sp. All these species can be considered as rare or accidental in flatheads, which were represented by 1, 2 and 2 individuals, respectively.

It is known that temporal variability in local environmental factors can regulate the survival and transmission success of infective stages, causing variations in parasite burdens (Pietrock and Marcogliese 2003), particularly for ectoparasitic species with monoxenous life cycles, but also for endoparasites either directly or via their effects on other host species. Temporal variability in the composition and structure of a parasite community are often caused by changes in either abiotic conditions (Zander 2005 ) and/or biological processes, such as migratory behaviour of definitive hosts. In the present study, seasonal variability was only observed in the occurrence of those parasites not reaching the status of component species. Although the low prevalence and abundance of these rare taxa precluded reliable statistical comparisons, most were adult stages living in the digestive tract. As such, seasonal oscillations of these parasites may result from changes in host diet. Many of these rare species could be considered as accidental infestations instead of members of the parasite fauna of $P$. brasiliensis.

On the other hand, almost all component species were long-lived stages, the exception being the ectoparasitic isopods and the endoparasites Lecithochirium microstomum and Moravecia argentinensis found at the adult stages in the gut and blood vessels, respectively. Component species showed fairly constant prevalence throughout the annual cycle and, with the exception of Hysterothylacium sp., the abundance of most parasites was also stable. Anisakid larvae, found in the body cavity of fishes, are known to be long-lived in fish hosts, and although their prevalence and abundance may vary over longer time scales, they remain stable for several years (McClelland and Marcogliese 1994). Therefore, seasonal changes should not be expected among fish of the same size or age. Hence, seasonality cannot account for the lower abundance of $\mathrm{Hys}$ terothylacium sp. in the winter sample, and other causes should be considered.

One explanation for the changing abundance of Hysterothylacium sp. in Mar del Plata fish could be a tem- porary immigration of flatheads from a neighbouring population. Infection levels of this parasite vary spatially among flathead populations. For example, the mean abundance of Hysterothylacium sp. in flatheads from El Rincón (2.7 worms per fish) (Braicovich and Timi 2008) is much lower than in fish from Mar del Plata (77.6 worms per fish in the whole sample). However, it seems unlikely that a neighbouring population of flatheads would be alike with respect to all parasite species except one. There are other helminths in flatheads that differ in abundance between El Rincón and Mar del Plata (e.g., Corynosoma australe, Anisakis simplex), but all showed constant values along the four seasons.

Certainly, the existence of variable oceanographic conditions in the study area is not in question. There are seasonal latitudinal oscillations of different water masses over the continental shelf of Buenos Aires province. This is particularly so in the coastal area between Necochea and Mar del Plata, which is alternately influenced by estuarine waters from El Rincón or the Río de la Plata and highly saline waters from San Matías Gulf, or continental shelf waters (Lucas et al. 2005), each with characteristic conditions of temperature and salinity, the two main determinants of the abundance and distribution of marine parasites (Esch and Fernández 1993). The latter water mass occupies the central portion of the shelf, with the exception of the coast between Necochea and Mar del Plata $\left(38^{\circ} 30^{\prime} \mathrm{S}\right.$ and $\left.37^{\circ} 30^{\prime} \mathrm{S}\right)$, where it reaches the coast due to the proximity of the $50 \mathrm{~m}$ isobath to the coast and the lack of locally formed coastal water (Lucas et al. 2005). Thus, the existence of a different population of $P$. brasiliensis inhabiting this water mass cannot be discounted. Further studies including samples from continental shelf waters are necessary to assess if this region is the source of immigrants and even to estimate the extent of the possible mixing among populations.

Although the causes of the seasonal variability in the abundance of Hysterothylacium sp. cannot be established, the fact that only one of the component species varied across seasons, and the absence of differences in prevalence for all of them, constitute strong evidence of the temporal persistence in species composition and abundance of parasite communities throughout an annual cycle. The seasonal stability observed in the parasite communities of $P$. brasiliensis was mainly determined by the contribution of the most abundant and prevalent species, Grillotia sp. and C. australe, to the average similarity both within and between seasons. The importance of both species as drivers of the structure of parasite assemblages is also reflected in their contribution to the dissimilarity values between pairs of seasons, which was, as expected, also determined by Hysterothylacium sp., although less consistently.

The overall seasonal stability of parasite communities of flathead in the study area was strongly in evi- 
dence in the convergent results of several multivariate analyses. Non-parametric similarity-based tests showed that within-season resemblance of parasite assemblages was comparable to between-season resemblance. Operating from very different assumptions, discriminant analyses showed the same basic trend. Although samples could be discriminated along the first discriminant function, this was a consequence of the seasonal variations in abundance of Hysterothylacium sp., which differentiated winter and summer samples along this axis. Two other important species, L. microstomum and A. simplex, were associated with the less important second discriminant function, which did not distinguish between seasons. Despite the distinguishing effects of these parasites, parasite communities of individual fish from all seasons clumped together in the bi-dimensional space and relatively few hosts could be correctly assigned to their season of capture, again showing the temporal homogeneity of parasite assemblages.

Since geographic distribution and community dynamics of marine parasites depend largely on environmental conditions (Esch and Fernández 1993, Rohde and Heap 1998, Luque et al. 2004), the seasonal stability of parasite assemblages of $P$. brasiliensis could be a consequence of constant oceanographic conditions in the study area. Fish assemblages in the northern Argentine coastal system show a remarkable degree of temporal persistence in species composition and geographical location, which has been attributed to the stability of factors such as temperature, depth and type of sediment (Jaureguízar et al. 2006). Furthermore, the dominance of larval stages in the parasite communities of flatheads, as well as in other fish species in the region (Timi 2007, Timi and Lanfranchi 2009, Lanfranchi et al. 2009), which can persist for long periods in their hosts, provides a certain degree of temporal inertia to these assemblages (Holmes 1990), increasing the effects of environmental homogeneity on the temporal stability of parasite community structure.

We have shown that the composition and structure of parasite communities of $P$. brasiliensis is seasonally repeatable, which is a prerequisite for spatial comparative studies. Although some degree of seasonal variability was observed in particular parasite species (such as Hysterothylacium sp.), these variations were vastly exceeded by the effect of the locality of capture, which also surpassed the influence of host size on the population attributes of parasite species. The discriminator species were the same as those found in a previous study of flatheads (Braicovich and Timi 2008), and have been also successfully used as biological tags for other host species in this region (Timi 2003, 2007, Sardella and Timi 2004, Timi et al. 2005, 2008, 2009). Consequently, seasonal predictability is also expected to occur in these parasites in other host species in the area, such as was recently observed for Pinguipes brasilianus (Timi et al. 2009). Thus, the parasites identified as suitable biological tags in the study area can be considered reliable and predictable markers for stock assessment, independently of the season of capture, at least on an annual scale.

Acknowledgements. The authors thank A. Jaureguízar and C. Carozza (Instituto Nacional de Investigación y Desarrollo Pesquero, Mar del Plata) for providing the samples from research cruises and to Sean Lucke for a critical revision of an earlier version of the manuscript. This work was supported by grants from CONICET (PIP No. 112-200801-00024), ANPCYT (PICT No. 02199) and Universidad Nacional de Mar del Plata (EXA 442/08).

\section{REFERENCES}

Altizer S., Dobson A., Hosseini P., Hudson P., Pascual M., Rohani P. 2006: Seasonality and the dynamics of infectious diseases. Ecol. Lett. 9: 467-484.

BegG G.A., Waldman J.R. 1999: An holistic approach to fish stock identification. Fish. Res. 43: 35-44.

Braicovich P.E., Etchegoin J.A., Timi J.T. 2009: Digenetic trematodes of the Brazilian flathead, Percophis brasiliensis Quoy et Gaimard, 1894 (Percophidae, Perciformes), from Argentinean and Uruguayan waters. Acta Parasitol. 54: 368-373.

Braicovich P.E., Timi J.T. 2008: Parasites as biological tags for stock discrimination of the Brazilian flathead Percophis brasiliensis in the south-west Atlantic. J. Fish Biol. 73: 557-571.

Brodgar 1.8. 2000: Software package for Multivariate Analysis and Multivariate Time series Analysis. Highland Statistics Ltd. Aberdeenshire, UK.

Bush A.O., Ано J.M., Kennedy C.R. 1990: Ecological versus phylogenetic determinants of helminth parasite community richness. Evol. Ecol. 4: 1-20.

Bush A.O., Lafferty K.D., Lotz J.M., Shostak A.W. 1997: Parasitology meets ecology on its own terms: Margolis et al. revisited. J. Parasitol. 83: 575-583.
Chambers C.B., Cribb T.H., Malcolm J.K. 2000: Tetraphyllidean metacestodes of teleosts of the Great Barrier Reef, and the use of in vitro cultivation to identify them. Folia Parasitol. 47: 285-292.

Chavez R.A., Valdivia I.M., Oliva M.E. 2007: Local variability in metazoan parasites of the pelagic fish species, Engraulis ringens: implications for fish stock assessment using parasites as biological tags. J. Helminthol. 81: 113-116.

Clarke K.R. 1993: Non-parametric multivariate analyses of changes in community structure. Aust. J. Ecol. 18: 117-143.

Clarke K.R., Gorley R.N. 2006: PRIMER V6: User Manual/ Tutorial. PRIMER-E, Plymouth, UK.

Cremonte F., Sardella N. 1997: The parasitofauna of Scomber japonicus Houttuyn, 1782 (Pisces: Scombridae) in two zones of the Argentine Sea. Fish. Res. 31: 1-9.

Díaz F., George-Nascimento M. 2002: Estabilidad temporal de las infracomunidades de parásitos en la borrachilla Scartichthys viridis (Valenciennes, 1836) (Pisces: Blennidae) en la costa central de Chile. Rev. Chil. Hist. Nat. 75: 641-649.

Esch G.W., Fernández J.C. 1993: A Functional Biology of Parasitism: Ecological and Evolutionary Applications. Chapman and Hall, London, 337 pp. 
GonzÁlez M.T., Poulin R. 2005: Spatial and temporal predictability of the parasite community structure of a benthic marine fish along its distributional range. Int. J. Parasitol. 35: 13691377.

Gotelli N.J., Rohde K. 2002: Co-occurrence of ectoparasites of marine fishes: a null model analysis. Ecol. Lett. 5: 86-94.

Holmes J.C. 1990: Helminth communities in marine fishes. In: G. Esch, A. Bush and J. Aho (Eds.), Parasite Communities: Patterns and Processes. Chapman and Hall, London, pp. 101-130.

Jaureguizar A.J., Menni R., Lasta C., Guerrero R. 2006: Fish assemblages of the northern Argentine coastal system: spatial patterns and their temporal variations. Fish. Oceanogr. 15: $326-344$.

Lanfranchi A.L., Rossin M.A., Timi J.T. 2009: Parasite infracommunities of a specialised marine fish species in a compound community dominated by generalist parasites. J. Helminthol. 83: $373-378$.

Lucas A.J., Guerrero R.A., Mianzán H.W., Acha E.M, Lasta C.A. 2005: Coastal oceanographic regimes of the Northern Argentine Continental Shelf $\left(34-43^{\circ} \mathrm{S}\right)$. Estuar. Coast. Shelf Sci. 65: 405-420.

Luque J.L., Muillot D., Poulin R. 2004: Parasite biodiversity and its determinants in coastal marine teleost fishes of Brazil. Parasitology 128: 671-682.

LuQue J.L., Poulin R. 2008: Linking ecology with parasite diversity in Neotropical fishes. J. Fish Biol. 72: 189-204.

MacKenzie K. 2002: Parasites as biological tags in population studies of marine organisms: an update. Parasitology 124: S153-S163.

MacKenzie K., Abaunza P. 1998: Parasites as biological tags for stock discrimination of marine fish: a guide to procedures and methods. Fish. Res. 38: 45-56.

McClelland G., Marcogliese D.J. 1994: Larval anisakine nematodes as biological indicators of cod (Gadus morhua) populations in the southern Gulf of St. Lawrence and on the Breton Shelf, Canada. Bull. Scand. Soc. Parasitol. 4: 97-116.

Mouillot D., George-Nascimento M., Poulin R. 2005: Richness, structure and functioning in metazoan parasite communities. Oikos 109: 447-460.

Pietrock M., Marcogliese D.J. 2003: Free-living endohelminth stages: at the mercy of environmental conditions. Trends Parasitol. 19: 293-299.

Poulin R. 2001: Interactions between species and the structure of helminth communities. Parasitology 122: 3-11.

Poulin R. 2004: Macroecological patterns of species richness in parasite assemblages. Basic Appl. Ecol. 5: 423-434.
Poulin R. 2007: Are there general laws in parasite ecology? Parasitology 134: 763-776.

Poulin R., Valtonen E.T. 2002: The predictability of helminth community structure in space: a composition of fish populations from adjacent lakes. Int. J. Parasitol. 32: 1235-1243.

Power A.M., Balbuena J.A., Raga J.A. 2005: Parasite infracommunities as predictors of harvest location of bogue (Boops boops L.): a pilot study using statistical classifiers. Fish. Res. 72: 229-239.

Rohde K., Heap M. 1998: Latitudinal differences in species and community richness and in community structure of metazoan endo- and ectoparasites of marine teleost fish. Int. J. Parasitol. 28: $461-474$

Sardella N.H., Timi J.T. 2004: Parasites of Argentine hake in the Argentine Sea: population and infracommunity structure as evidences for host stock discrimination. J. Fish Biol. 65: $1472-1488$.

Timi J.T. 2003: Parasites of Argentine anchovy in the south-west Atlantic: latitudinal patterns and their use for discrimination of host populations. J. Fish Biol. 63: 90-107.

TiмI J.T. 2007: Parasites as biological tags for stock discrimination in marine fish from South American Atlantic waters. J. Helminthol. 81: 107-111.

Timi J.T., Lanfranchi A.L. 2009: The importance of the compound community on the parasite infracommunity structure in a small benthic fish. Parasitol. Res. 104: 295-302.

Timi J.T., Lanfranchi A.L., Etchegoin J.A. 2009: Seasonal stability and spatial variability of parasites in Brazilian sandperch from the northern Argentine sea: evidence for stock discrimination. J. Fish Biol. 74: 1206-1225.

Timi J.T., Lanfranchi A.L., Etchegoin J.A., Cremonte F. 2008: Parasites of the Brazilian sandperch, Pinguipes brasilianus $\mathrm{Cu}-$ vier: a tool for stock discrimination in the Argentine Sea. J. Fish Biol. 72: 1332-1342.

Timi J.T., Luque J.L., Sardella N.H. 2005: Parasites of Cynoscion guatucupa along South American Atlantic coasts: evidence for stock discrimination. J. Fish Biol. 67: 1603-1618.

Vidal-Martínez V.M., Poulin R. 2003: Spatial and temporal repeatability in parasite community structure of tropical fish hosts. Parasitology 12: 387-398.

Walther B.A., Cotgreave P., Price R.D., Gregory R.D., Clayton D.H. 1995: Sampling effort and parasite species richness. Parasitol. Today 11: 306-310.

ZANDER C.D. 2005: Four-year monitoring of parasite communities in gobiid fishes of the southwest Baltic. III. Parasite species diversity and applicability of monitoring. Parasitol. Res. 95: 136-144.

Accepted 8 April 2010 